\title{
Assessment of Early Sexual Initiation and Associated Factors among Preparatory School Students of FaggetaLekoma District, Awi Zone, Northwest Ethiopia, 2015
}

\author{
Dessalew Bizu1, Zewdie Aderaw ${ }^{1}$, Getachew Mullu Kassa ${ }^{2 *}$ \\ ${ }^{1}$ Public Health Department, Medicine and Health Science College, Debre Markos University, Debre Markos, \\ Ethiopia \\ ${ }^{2}$ Midwifery Department, Medicine and Health Science College, Debre Markos University, Debre Markos, \\ Ethiopia \\ Email: desalewbizu@gmail.com, zewdiew1984@gmail.com, "'gechm2005@gmail.com
}

Received 7 July 2015; accepted 3 August 2015; published 6 August 2015

Copyright (C) 2015 by authors and Scientific Research Publishing Inc.

This work is licensed under the Creative Commons Attribution International License (CC BY).

http://creativecommons.org/licenses/by/4.0/

(c) (i) Open Access

\begin{abstract}
Introduction: Almost half of the world's population is concentrated under the age of less than 25 years. The highest number of this population is living in developing countries. Sub-Saharan Africa youths constitute $20 \%-30 \%$ of this population. Early sexual initiation is common among young people, and it has several sexual and reproductive health consequences. So, the objective of this research was to assess the prevalence of early sexual initiation and associated factors among preparatory school students of FaggetaLekoma district, Awi zone, Northwest Ethiopia, 2015. Methods and Materials: Institutional based cross-sectional study design with stratified sampling technique was used. Completeness of questionnaires was checked visually and data were coded and entered into Epi-Info version 3.5.4. and transported to SPSS version 16 software package for analysis. Bivariate and multivariate logistic regression was used to determine factors associated with early sexual initiation at $95 \%$ confidence interval. Result: A total of 270 students were included in the study. The mean age of the respondents was $18.82 \pm 1.91$ years, of which $117(43.3 \%)$ were females, and $156(57.8 \%)$ were rural residents. Among the total students who attended their class within the study period, $55(20.4 \%)$ students had early sexual initiation. The results of multivariable model revealed that age AOR $=4.38,95 \%$ CI $(1.75-10.94)$, grade $A O R=4.18,95 \%$ CI $(1.58$ 11.04), existence of a boy/girl friend $O R=8.56,95 \%$ CI $(3.16-23.14)$, parental supervision AOR = $0.20,95 \% \mathrm{CI}(0.04-0.94)$ and peer pressure $\mathrm{AOR}=3.56,95 \% \mathrm{CI}(1.31-9.66)$ were found to be significantly associated with early sexual initiation in multivariable analysis with P-value $<0.05$.
\end{abstract}

"Corresponding author.

How to cite this paper: Bizu, D., Aderaw, Z. and Kassa, G.M. (2015) Assessment of Early Sexual Initiation and Associated Factors among Preparatory School Students of FaggetaLekoma District, Awi Zone, Northwest Ethiopia, 2015. International Journal of Clinical Medicine, 6, 521-529. http://dx.doi.org/10.4236/ijcm.2015.68070 
Conclusion and Recommendation: The current study found that early sexual initiation is still the problem. Among those who had initiated sex early, most of them had sex within the past 12 months, most of them had sex with their boy/girl friends and majority of them did not use condom. Age, grade, existence of a boy/girl friend, parental supervision and peer pressure of respondents were factors affecting early sexual initiation in the study area. In order to reduce early sexual initiation in preparatory school students, stakeholders should prioritize to educate young peoples, couples, and parents about sexual and reproductive health issues.

\section{Keywords}

Early Sex, Early Sexual Initiation, Young People, Preparatory Students, Ethiopia

\section{Introduction}

Worldwide early sexual initiation exposes to a high rate of reproductive health problems such as HIV infection, sexually transmitted infections, unwanted pregnancy and pregnancy related complications. During this age, pregnancy related complications are aggravated by physiological immaturity [1]. Studies have shown that the earlier sexual engagement is related with the higher risk of acquiring STIs and getting pregnant compared to adults [2]-[4].

Early sexual engagement may also hinder international initiatives such as reducing maternal and child mortality and morbidity, universal education for all and reduction of poverty by promoting a high number of early child bearings coupled with larger population growth [5] [6].

Early sexual initiation is among the most contributors of high population growth in Ethiopia. Despite the definition of sexual initiation being differently used in different literatures, in Ethiopia early sexual initiation is defined as having sexual intercourse before the age of 18 years [4]. Practicing sexual intercourse before the age of 18 years has a lot of health problems such as getting infected with human immune deficiency virus, unwanted pregnancy, other sexually transmitted diseases and fistula because girls before the age of 18 years may not be physiologically ready to practice sexual intercourse and give birth [5].

Even though the health policy of Ethiopia gives due attention for youth reproductive health, problems related to early sexual initiation are still very high. For instance, according to 2011 EDHS, $29 \%$ of women started sexual intercourse before the age of 15 years and $62 \%$ before the age of 18 years [7].

Therefore, the aim of this research was to assess the level of early sexual initiation and its associated factors among Addis Kidam preparatory school students.

\section{Materials and Methods}

\subsection{Study Design, Area and Period}

Institutional based cross-sectional study design was used. FaggetaLekoma district was located in Awi zone, Amhara region. It was located at the north western part of Ethiopia, about 465 kilometers from Addis Ababa and 108 kilometers from Bahir Dar. The district had 1 preparatory school. The school had grade 11 with 13 sections and grade 12 with 9 sections. The numbers of students attending the school were 932, of which 504 were males and 428 were females [8]. This study was conducted on 1-3 February 2015.

\subsection{Source Population}

All preparatory school students attending Addis Kidam preparatory school in FaggetaLekoma district during the study period were included in the study. Students who were sick and absent during data collection were excluded from the study.

\subsection{Sample Size Determination}

The sample size was calculated using a single population proportion formula designated as:

$$
n=\left(Z_{\sigma / 2}\right)^{2} p(1-p) /(d)^{2}
$$


where: $n=$ the required sample size, $Z_{\alpha / 2}=95 \%$ confidence interval (level of significance) (1.96).

$P=$ Expected proportion of the population (proportion of early sexual initiation is $37.7 \%$ which is taken from a recent finding among preparatory school students in Northwest Ethiopia [9], and $d=$ desired precision (the margin of error) $(5 \%)$.

$$
\begin{aligned}
& n=(1.96)^{2} * 0.377(1-0.377) /(0.05)^{2} \\
& n=361 \text {. }
\end{aligned}
$$

But since the total number of students in Addis Kidam preparatory school is 932 which is less than 10,000, population correction formula was used to get the sample size. Therefore,

Corrected sample size is $=n /(1+n-1 / N)$

$=361 /(1+(361-1 / 932))$

$=260$

Ten percent was also added for non-response rate. Accordingly the required sample size was $260+260 \times$ $10 \%=286$. Therefore, the final sample size was 286 .

\subsection{Sampling Procedure and Technique}

Since this research considers early sexual initiation as having sexual intercourse before the age of 18 years, there was heterogeneity in early sexual initiation across male and female students. Therefore, this study utilized stratified sampling technique to select the study subjects. The students were classified into male and female strata and study participants from each stratum were selected proportionally using systematic random sampling technique.

\subsection{Variables of the Study}

The dependent variable of the study was early sexual initiation, and the independent variables were: socio demographic characteristics like; sex, age, residence, marital status etc., and behavioral characteristics like; alcohol drinking, use of drugs, smoking, kchat chewing, viewing of pornography, family discussion on sexual and reproductive health issues, peer pressure etc.

\subsection{Data Collection Tools and Procedures}

A structured self-administered questionnaire was used to collect data on socio-demographic and behavioral characteristics. The tool was adapted from tools used to assess early sexual initiation used by different studies [7] [10] [11]. The questionnaire was primarily prepared in English and translated to Amharic. The data was collected by 5 data collectors who were diploma clinical nurses and supervised by two BSC nurses for three consecutive days. The data collectors and two supervisors trained for one day on how to interview and how to fill the questionnaire based on a prepared instruction. The tool was pretested 7 days before the actual data collection at $5 \%$ of the total sample among Dangila preparatory school students.

The quality of data was assured by proper designing and pre-testing of the questionnaires 7 days before the actual data collection at Dangila preparatory school students on 5\% of participants, and by giving training for the data collectors and supervisors before the actual data collection. Every day after data collection, questionnaires were reviewed and checked for completeness and relevance by the supervisors and principal investigator and the necessary feedback was offered to data collectors in the next morning.

\subsection{Data Processing and Analysis Procedures}

Completeness of questionnaires was checked visually and data was coded and entered into Epi-Info version 3.5.4 and transported to SPSS version 16 software package for analysis. For controlling errors $10 \%$ of the questionnaire was double entered, also frequency checks were done.

The data was analyzed using binary logistic regression to determine the effect of various factors on the outcome variable. Variables with P-value $<0.2$ in bivariate analysis were entered to multivariate analysis. The results were presented in the form of tables, figures and text using frequencies and summary statistics such as mean, standard deviation and percentage to describe the study population in relation to socio-demographic and behavioral variables. The degree of association between independent and dependent variables were assessed using odds ratio with $95 \%$ confidence interval. Bivariate and multivariate analysis was applied by running through logistic regression. 


\subsection{Ethical Considerations}

Ethical clearance for the proposed research was obtained from research committee of Debre Markos University, college of medicine and health science. Respondents were informed on the purpose of the study, and written informed consent was obtained. All information obtained from the study participants was kept confidential.

\section{Results}

\subsection{Socio-Demographic Characteristics}

A total of 270 out of 286 students attending their class at Addis Kidamie preparatory school responded to the questionnaire with a response rate of $94.4 \%$. Of the total respondents $117(43.3 \%)$ were females. The mean age of the respondents was $18.82 \pm 1.91$ years. Majority of the study participants $156(57.8 \%)$ were from rural areas. $195(72.2 \%)$ of the study participants were from Agew ethnicity (Table 1).

Table 1. Socio demographic characteristics of respondents towards early sexual initiation in FaggetaLekoma District, Awi zone, North West Ethiopia, $2015(n=270)$.

\begin{tabular}{|c|c|c|c|}
\hline Variable & Category & Frequency & Percentage \\
\hline \multirow{2}{*}{ Current place of residence } & Urban & 114 & 42.2 \\
\hline & Rural & 156 & 57.8 \\
\hline \multirow{2}{*}{ Sex } & Male & 153 & 56.7 \\
\hline & Female & 117 & 43.3 \\
\hline \multirow{2}{*}{ Age } & $15-19$ & 200 & 74.1 \\
\hline & $20-24$ & 70 & 25.9 \\
\hline \multirow{2}{*}{ Ethnicity } & Agew & 195 & 72.2 \\
\hline & Amhara & 75 & 27.8 \\
\hline \multirow{3}{*}{ Marital status } & single & 234 & 86.7 \\
\hline & Married & 33 & 12.2 \\
\hline & Divorced & 3 & 1.1 \\
\hline \multirow{4}{*}{$\begin{array}{l}\text { Educational status of } \\
\text { students' mothers }\end{array}$} & Unable to read \& write & 159 & 58.9 \\
\hline & Able to read \& write & 90 & 33.3 \\
\hline & Primary education $(1-8)$ & 15 & 5.6 \\
\hline & Secondary education and above $(9-12+)$ & 6 & 2.2 \\
\hline \multirow{4}{*}{$\begin{array}{l}\text { Educational status of } \\
\text { students' fathers }\end{array}$} & Unable to read \& write & 84 & 31.1 \\
\hline & Able to read \& write & 99 & 36.7 \\
\hline & Primary education $(1-8)$ & 35 & 13.0 \\
\hline & Secondary education and above $(9-12+)$ & 52 & 19.3 \\
\hline \multirow{3}{*}{$\begin{array}{l}\text { Occupational status of } \\
\text { students' mothers }\end{array}$} & House wife & 230 & 85.2 \\
\hline & Employed (government, private) & 18 & 6.7 \\
\hline & Merchant & 22 & 8.1 \\
\hline \multirow{3}{*}{$\begin{array}{l}\text { Occupational status of } \\
\text { students' fathers }\end{array}$} & Farmer & 174 & 64.4 \\
\hline & Employed (government, private) & 42 & 15.6 \\
\hline & Merchant & 54 & 20.0 \\
\hline \multirow{2}{*}{ Grade } & $11^{\text {th }}$ & 142 & 52.6 \\
\hline & $12^{\text {th }}$ & 128 & 47.4 \\
\hline \multirow{2}{*}{ Living condition } & Alone & 164 & 60.7 \\
\hline & With family & 106 & 39.3 \\
\hline
\end{tabular}


Regarding to marital status 234 (86.7\%) single, 33 (12.2\%) were married, 3 (1.1\%) divorced. 142 (52.6\%) of the study participants were grade $11,159(58.9 \%)$ of student' mothers and $84(31.1 \%)$ students 'fathers educational status was unable to read and write. Majority 230 (85.2\%) of students' mothers and 174 (64.4\%) students' fathers occupational status was house wife and farmer respectively (Table 1).

\subsection{Behavioral Characteristics}

Among the total study participants, 214 (79.3\%) study participants did not have boy/girl friends and one 172 $(63.7 \%)$ did not have viewed pornographic movies. Regarding to reproductive health issues, $202(74.8 \%)$ of students responded that there was no family discussion, 199 (73.7\%) had no parental supervision and 200 (74\%) had peer pressure towards early sexual initiation. Among the total study participants, 264 (97.8\%) of the study participants did not smoke cigarette and $6(2.2 \%)$ smoked sometimes within the past 12 months but did not smoke within the past 30 days. In this research none of the study participants were found to be Kchat chewers and drug addicts (Table 2).

Table 2. Behavioral characteristics of respondents towards early sexual initiation in FaggetaLekoma district, Awi zone, North West Ethiopia, $2015(n=270)$.

\begin{tabular}{|c|c|c|c|}
\hline Variable & Category & Frequency & Percentage \\
\hline \multirow{2}{*}{ Drinking alcohol } & No & 139 & 51.5 \\
\hline & Yes & 131 & 48.5 \\
\hline \multirow{2}{*}{ Drinking within the past 12 months } & No & 0 & 0 \\
\hline & Yes & 131 & 48.5 \\
\hline \multirow{2}{*}{ Drinking within the past 30 day } & No & 42 & 15.6 \\
\hline & Yes & 89 & 33.0 \\
\hline \multirow{3}{*}{ Degree of drinking } & Always & 0 & 0 \\
\hline & Sometimes & 119 & 44.1 \\
\hline & Stopped sometime before & 12 & 4.4 \\
\hline \multirow{2}{*}{ Smoking status } & No & 264 & 97.8 \\
\hline & Yes & 6 & 2.2 \\
\hline \multirow{3}{*}{ Smoking within the past 12 months (6) } & No & 0 & 0 \\
\hline & Yes & 6 & 100 \\
\hline & No & 6 & 100 \\
\hline \multirow[t]{2}{*}{ Smoking within the past 30 days (6) } & Yes & 0 & 0 \\
\hline & Sometimes & 6 & 100 \\
\hline \multirow{2}{*}{ Kchat chewing } & No & 270 & 100 \\
\hline & Yes & 0 & 0 \\
\hline \multirow{2}{*}{ Drug use } & No & 270 & 100 \\
\hline & Yes & 0 & 0 \\
\hline \multirow{2}{*}{ Existence of a boy/girl friend } & No & 214 & 79.3 \\
\hline & Yes & 56 & 20.7 \\
\hline \multirow{2}{*}{ Exposure to pornographic movies } & No & 172 & 63.7 \\
\hline & Yes & 98 & 36.3 \\
\hline \multirow{2}{*}{$\begin{array}{l}\text { Existence of open family discussion } \\
\text { about reproductive health issues }\end{array}$} & No & 202 & 74.8 \\
\hline & Yes & 68 & 25.2 \\
\hline \multirow{2}{*}{ Parental supervision } & No & 199 & 73.7 \\
\hline & Yes & 71 & 26.3 \\
\hline \multirow[t]{2}{*}{ Peer pressure } & No & 200 & 74.1 \\
\hline & Yes & 70 & 25.9 \\
\hline
\end{tabular}




\subsection{Level of Early Sexual Initiation}

Out of 270 interviewed students attending their class at Addis Kidamie preparatory school, 55 (20.4\%) had initiated sex before their eighteenth birthday, out of which $35(63.6 \%)$ and $20(36.4 \%)$ were male and female respectively (Figure 1).

Among those who had initiated sex early, 30 (54.5\%) of them had sex within the past 12 months. Out of the total students who initiated sex early, $32(58.2 \%), 17(30.9 \%)$ and $6(10.9 \%)$ of respondents first sexual partner was with their boy/girl friends, actual husband/wife and commercial sex worker respectively. Of those who initiated sex early, $37(67.3 \%)$ did not use condom and 31 (56.4\%) had one, $21(38.2 \%)$ had two and 3 (5.4\%) of them had three or more sexual partners respectively (Table 3 ).

\subsection{Factors Associated with Early Sexual Initiation}

Early sexual initiation among Addis Kidamie preparatory school students varied under the influence of various factors. This test gave a preliminary foothold for further investigation of the explanatory variables to see their net effects by multivariable analysis with the control of confounders. Accordingly; place of residence COR $=$ $2.04,95 \%$ CI $(1.07-3.87)$, age COR $=8.050,95 \%$ CI $(4.19-15.43)$, grade COR $=5.48,95 \%$ CI (2.73 - 10.99), educational status of a father $\mathrm{COR}=2.25,95 \% \mathrm{CI}(0.97-5.17)$, viewing pornographic movies $\mathrm{COR}=2.36,95 \%$ CI (1.29 - 4.30), existence of a boy/girl friend COR $=5.53,95 \%$ CI $(2.872-10.64)$, parental supervision COR $=$ $0.12,95 \% \mathrm{CI}(0.03-0.41)$, family discussion $\mathrm{COR}=0.13,95 \% \mathrm{CI}(0.04-0.44)$ and peer pressure COR $=2.84$, $95 \%$ CI (1.52 - 5.31) were found to have P-value $<0.2$ in which this variables were taken to multivariable analysis.

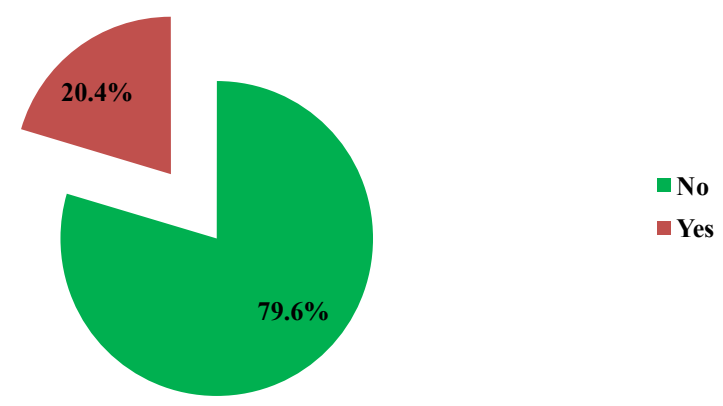

Figure 1. Prevalence of early sexual initiation among preparatory school students in FaggetaLekoma district, Awi zone, North West Ethiopia, $2015(n=270)$.

Table 3. Characteristics of sexually exposed preparatory school students in FaggetaLekoma district, Awi zone, North West Ethiopia April, $2015(n=61)$.

\begin{tabular}{|c|c|c|c|}
\hline Variable & Category & Frequency & Percentage \\
\hline \multirow{3}{*}{$\begin{array}{l}\text { First sex sexual partner for students who } \\
\text { had sex }(n=61)\end{array}$} & Actual or future husband/wife & 17 & 27.9 \\
\hline & Boy/girl friend & 38 & 62.3 \\
\hline & Commercial sex workers & 6 & 9.8 \\
\hline \multirow{2}{*}{ Use of condom during first sex $(n=61)$} & No & 43 & 70.5 \\
\hline & Yes & 18 & 29.5 \\
\hline \multirow{3}{*}{ Number of sexual partners ever $(n=61)$} & One & 37 & 60.7 \\
\hline & Two & 21 & 34.4 \\
\hline & Three and above & 3 & 4.9 \\
\hline \multirow{2}{*}{ Had sex within the past 12 months $(n=61)$} & No & 31 & 50.8 \\
\hline & Yes & 30 & 49.2 \\
\hline
\end{tabular}


The results of multivariable model revealed that age AOR $=4.38,95 \% \mathrm{CI}(1.75-10.94)$, grade $\mathrm{AOR}=4.18$, $95 \%$ CI $(1.58-11.04)$, existence of a boy/girl friend AOR $=8.56,95 \%$ CI $(3.16-23.14)$, parental supervision $\mathrm{AOR}=0.20,95 \% \mathrm{CI}(0.04-0.94)$ and peer pressure $\mathrm{AOR}=3.56,95 \% \mathrm{CI}(1.31-9.66)$ were found to be significantly associated with early sexual initiation in multivariable analysis with P-value $<0.05$ (Table 4).

\section{Discussion}

In this research 55 (20.4\%) out of 270 study participants had early sexual initiation. This finding was higher than the finding from china $4.8 \%$ but lower than the findings from Nigeria Port Harcourt university undergraduate students $52 \%$, Ghanaian youth $25 \%$, Ethiopia Addis Ababa University under graduate students $27.4 \%$, GamoGofa 56.9\%, Humera 63.3\%, north east Ethiopia 51\%, north west Ethiopia 37.7\% and 2011 EDHS 29\% [9] [11]-[19]. The possible explanation for this finding being higher than the finding from china might be due to the fact that students attending their class in china may have access to means of media and the family support provided towards students in china might be better than in Ethiopia but being lower than the findings in Nigeria, Ghana and Ethiopia might be attributable to sample size, study period, educational level of study participants.

Students with age between $15-19$ years were 4.38 times more likely to start early sexual initiation compared to those with $20-24$ years old $\mathrm{AOR}=4.38,95 \% \mathrm{CI}(1.75-10.94)$. This finding is supported by findings from Northern Thailand and Kenya [20] [21]. The possible explanation for this finding is due to the fact that majority of study participants' age was in the age group between $15-19$ years and the result might change as age group of study participants' changes to $20-24$ years.

Table 4. Bivariate and multivariable logistic regression results on factors associated with early sexual initiation in FaggetaLekoma district, Awi zone, North West Ethiopia April, $2015(n=270)$.

\begin{tabular}{|c|c|c|c|c|c|c|}
\hline \multirow{2}{*}{ Variable } & \multirow{2}{*}{ Category } & \multicolumn{2}{|c|}{ Early sexual initiation } & \multirow{2}{*}{ COR $(95 \% \mathrm{CI})$} & \multirow{2}{*}{$\operatorname{AOR}(95 \% \mathrm{CI})$} & \multirow{2}{*}{ P-value } \\
\hline & & No & Yes & & & \\
\hline \multirow{2}{*}{ Place of residence } & Urban & 98 & 16 & 1 & 1 & \\
\hline & Rural & 117 & 39 & $2.04(1.07-3.87)$ & $2.85(1.040-7.81)$ & 0.092 \\
\hline \multirow{2}{*}{ Age } & $15-19$ years & 179 & 21 & 1 & 1 & \\
\hline & $20-24$ years & 36 & 34 & $8.05(4.19-15.43)$ & $4.38(1.75-10.94)^{* *}$ & 0.002 \\
\hline \multirow{4}{*}{ Fathers educational status } & Unable to read and write & 63 & 21 & 1 & 1 & \\
\hline & Able to read and write & 80 & 19 & $0.71(0.35-1.43)$ & $0.95(0.37-2.42)$ & 0.930 \\
\hline & Primary education $(1-8)$ & 20 & 15 & $2.25(0.97-5.17)$ & $2.09(0.52-8.33)$ & 0.296 \\
\hline & Secondary education $(9-12+)$ & 52 & 0 & 0 & 0 & 0.997 \\
\hline \multirow{2}{*}{ Grade } & $11^{\text {th }}$ & 130 & 12 & 1 & 1 & \\
\hline & $12^{\text {th }}$ & 85 & 43 & $5.48(2.73-10.99)$ & $4.18(1.58-11.04)^{* *}$ & 0.004 \\
\hline \multirow{2}{*}{$\begin{array}{l}\text { Existence of a boy/girl } \\
\text { friend }\end{array}$} & No & 185 & 29 & 1 & 1 & \\
\hline & Yes & 30 & 26 & $5.53(2.87-10.64)$ & $8.56(3.16-23.14)^{*}$ & 0.000 \\
\hline \multirow{2}{*}{$\begin{array}{l}\text { Exposure to pornographic } \\
\text { movies }\end{array}$} & No & 146 & 26 & 1 & & \\
\hline & Yes & 69 & 29 & $2.36(1.29-4.30)$ & $1.28(0.48-3.46)$ & 0.614 \\
\hline \multirow{2}{*}{$\begin{array}{l}\text { Existence of open family } \\
\text { discussion about sexual and } \\
\text { reproductive health issues }\end{array}$} & No & 150 & 52 & 1 & 1 & \\
\hline & Yes & 65 & 3 & $0.13(0.04-0.44)$ & $1.03(0.02-39.88)$ & 0.985 \\
\hline \multirow{2}{*}{ Parental supervision } & No & 147 & 52 & 1 & 1 & \\
\hline & Yes & 68 & 3 & $0.12(0.03-0.41)$ & $0.20(0.04-0.94)^{* *}$ & 0.043 \\
\hline \multirow{2}{*}{ Peer pressure } & No & 169 & 31 & 1 & 1 & \\
\hline & Yes & 46 & 24 & $2.84(1.52-5.31)$ & $3.56(1.31-9.66)^{* *}$ & 0.012 \\
\hline
\end{tabular}

Significant at ${ }^{*}$ P-value $<0.001 ;{ }^{* *}$ P-value $<0.05$. 
Those who were attending their class at $12^{\text {th }}$ grade were 4.18 times more likely to start early sexual initiation compared to those attending their class at $11^{\text {th }}$ grade AOR $=4.18,95 \%$ CI $(1.58-11.04)$. This might be due to the fact that grade $12^{\text {th }}$ students may think that grade 12 is the last chance for them to have sexual aspiration irrespective of their age.

Participants who had a boy/girl friend were 8.56 times more likely to start early sexual initiation compared to those who did not have a boy/girl friend AOR $=8.56,95 \% \mathrm{CI}(3.16-23.14)$. This finding was in line with a document from International parenthood planned Federation [22]. The possible explanation for this finding could be those who had boy/girl friends might start sex early because their counterpart could initiate them to exercise sexual intercourse without their will.

Students who had parental supervision were $80 \%$ less likely to start early sexual initiation compared to those who did not have parental supervision $\mathrm{AOR}=0.20,95 \% \mathrm{CI}(0.04-0.94)$. This finding was in line with the finding from Kenya [21]. This might happen due to the fact that parents are the ones to teach and help students and in turn students may respect their parents and respect parent' orders.

Those who responded that peer pressure could affect sexual initiation were 3.56 times more likely to start early sexual initiation compared to those who thought that peer pressure could not affect sexual initiation AOR $=$ $3.56,95 \%$ CI (1.31 - 9.66). This finding is also in line with a finding from Ethiopia [23]. The possible explanation for this finding might be due to the fact that those who thought that peer pressure could affect sexual initiation might start sex early not because of their need, but due to the pressure exerted by their friends to start sexual intercourse.

\section{Conclusions}

This finding showed that magnitude of early sexual initiation in this study area was still high. Among those who had initiated sex early, more than half of them had sex within the past 12 months. Some of the respondents who started sex early had sex with commercial sex workers and majority of them did not use condom.

Age, grade, existence of a boy/girl friend, parental supervision, and peer were found to be factors affecting early sexual initiation in the study area.

\section{Recommendations}

Based on the above findings the following recommendations are forwarded to reduce early sexual initiation in preparatory school students:

$>$ Ministry of education should strengthen efforts to teach students about reproductive health issues and should create a strategy for students to share experiences across grades;

> Ministry of health should implement youth friendly services in schools, and should create in school and out of school mechanisms to counsel couples on reproductive health issues;

$>$ Parents should discuss with their children openly about sexual and reproductive health issues and should consult school community about status of their children;

> Schools should create a suitable environment for their students to discuss and learn about sexual and reproductive health issues, and should identify and tackle behaviors that could motivate students for early sexual initiation;

Researchers should conduct further researches to investigate, why early sexual initiation is still a challenge in Ethiopia.

\section{Acknowledgements}

We would like to acknowledge to Debre Markos University, College of Medicine and Health Science, to Data collectors, supervisors and study participants.

\section{References}

[1] Tenkorang, E.Y. and Maticka-Tyndale, E. (2008) Factors Influencing the Timing of First Sexual Intercourse Among Young People in Nyanza, Kenya. International Family Planning Perspectives, 34, 177-188. http://dx.doi.org/10.1363/3417708

[2] Key Statistics from the National Survey of Family Growth. National Center for Health Statistic. 
http://www.cdc.gov/nchs/nsfg/key statistics/s.htm\#vaginalsexual

[3] Kaestle, C.E., Halpern, C.T., Miller, W.C. and Ford, C.A. (2005) Young Age at First Sexual Intercourse and Sexually Transmitted Infections in Adolescents and Young Adults. American Journal of Epidemiology, 161, 774-780. http://dx.doi.org/10.1093/aje/kwi095

[4] Zimmer-Gembeck, M.J. and Helfand, M. (2008) Ten Years of Longitudinal Research on US Adolescent Sexual Behavior: Developmental Correlates of Sexual Intercourse, and the Importance of Age, Gender and Ethnic Background. Developmental Review, 28, 153-224.

[5] Mensch, B.S., Grant, M.J. and Blanc, A.K. (2006) The Changing Context of Sexual Initiation in Sub-Saharan Africa. Population and Development Review, 32, 699-727.

[6] Kalamuss, D., Davidson, A., Cohall, A., Laraque, D. and Cassell, C. (2003) Preventing Sexual Risk Behaviors and Pregnancy among Teenagers: Linking Research and Programs. Perspectives on Sexual and Reproductive Health, 35, 87-93. http://dx.doi.org/10.1363/3508703

[7] FDRE; Federal Negarit Gazetta Extra Ordinary Issue No. 1/2000; The Revised Family Code Proclamation No. 213/2000; Addis Ababa 4th Day of July, 2000.

[8] Addis Kidame Preparatory School. 1st Quarter Report, September 2014.

[9] Habtamu, M.B., Direslgne, M.A. and Hailu, F.D. (2015) Assessment of Time of Sexual Initiation and Its Associated Factors among Students in Northwest Ethiopia. Science Journal of Public Health, 3, 10-18. http://dx.doi.org/10.11648/j.sjph.20150301.13

[10] Jeremić, V., Matejić, B., Soldatović, I. and Radenović, S. (2014) Early Sexual Initiation and Risk Factors in Serbian Adolescents: Data from the National Health Survey. The European Journal of Contraception and Reproductive Health Care, 19, 211-219.

[11] Central Statistical Agency (2012) Ethiopian Demographic and Health Survey. Addis Ababa, Ethiopia and Calverton, Maryland, USA.

[12] Daniyam, C.A., Agaba, P.A. and Agaba, E.I. (2010) Sexual Behavior of Medical Students: A Single Institutional Survey. African Health Sciences, 10, 150-153.

[13] Doku, D. (2012) Substance Use and Risky Sexual Behaviours among Sexually Experienced Ghanaian Youth. BMC Public Health, 12, 571. http://dx.doi.org/10.1186/1471-2458-12-571

[14] Tilahun, M.Y., Worku, A.Y., Bogale, A.M. and Semahegn, A.D. (2014) Sexual Initiation and Factors Associated with It among Addis Ababa University Undergraduate Students, Addis Ababa, Ethiopia. American Journal of Health Research, 2, 260-270. http://dx.doi.org/10.11648/j.ajhr.20140205.17

[15] Tilahun, M. and Ayele, G. (2013) Association of Khat and Alcohol Use with HIV Infection and Age at First Sexual Initiation among Youths Visiting HIV Testing and Counseling Centers in Gamo-Gofa Zone, South West Ethiopia. Science Journal of Public Health, 13, 10.

[16] Fekadu, A.D. and Gebrethadkan, F.T. (2014) Risky Sexual Behavior and Associated Factors among Grade 9-12 Students in Humera Secondary School, Western Zone of Tigray, NW Ethiopia, 2014. Science Journal of Public Health, 2 , 410-416. http://dx.doi.org/10.11648/j.sjph.20140205.16

[17] Chi, X., Yu, L. and Winter, S. (2012) Prevalence and Correlates of Sexual Behaviors among University Students: A Study in Hefei, China. BMC Public Health, 12, 972-981. http://dx.doi.org/10.1186/1471-2458-12-972

[18] Imaledo, A.J., Peter-Kio, B.O. and Asuquo, O.E. (2012) Pattern of Risky Sexual Behavior and Associated Factors among Undergraduate Students of the University of Port Harcourt, Rivers State, Nigeria. Pan African Medical Journal, 12, 97.

[19] Mazengia, F. and Worku, A. (2009) Age at Sexual Initiation and Factors Associated with It among Youths in North East Ethiopia. Ethiopian Journal of Health Development, 23, 154-162.

[20] Liu, A., Kilmarx, P., Jenkins, R.A., Manopaiboon, C., Mock, P.A., Jeeyapunt, S., Uthaivoravit, W. and van Griensven, F. (2006) Sexual Initiation, Substance Use, and Sexual Behavior and Knowledge among Vocational Students in Northern Thailand. International Family Planning Perspectives, 32, 126-135. http://dx.doi.org/10.1363/3212606

[21] Rudatsikira, E., Ogwell, Aeo., Siziya, S. and Muula, A.S. (2007) Prevalence of Sexual Intercourse among SchoolGoing Adolescents in Coast Province, Kenya. Tanzania Health Research Bulletin, 9, 159-163.

[22] International Planned Parenthood Federation and the Forum on Marriage and the Rights of Women and Girls; Ending Child Marriage; a Guide for Global Policy Action. www.ippf.org

[23] Dingeta, T., Oljira, L. and Assefa, N. (2012) Patterns of Sexual Risk Behavior among Undergraduate University Students in Ethiopia: A Cross-Sectional Study. Pan African Medical Journal, 12, 1-9. 